\title{
Correction to: Alcohol consumption and its associated factors among pregnant women in Sub-Saharan Africa: A systematic review and meta-analysis
}

Alemu Earsido Addila ${ }^{1,2^{*}}$, Telake Azale Bisetegn ${ }^{3}$, Yigzaw Kebede Gete ${ }^{2}$, Mezgebu Yitayal Mengistu ${ }^{4}$ and Getnet Mihretie Beyene $e^{2,5}$

Correction to: Subst Abuse Treat Prev Policy 15, 29 (2020)

\section{http://orcid.org/10.1186/s13011-020-00269-3}

Following publication of the original article [1], we have been notified that there is a mistake in the title of the article.

Currently the title is: Alcohol consumption and its associated factors among pregnant women in Sub-Saharan Africa: a systematic review and meta-analysis' as given in the submission system. It should be changed to: Alcohol consumption and its associated factors among pregnant women in Sub-Saharan Africa: A systematic review and meta-analysis.

\footnotetext{
Author details

'Department of Public Health, College of Medicine and Health Sciences, Wachemo University, Hossana, Ethiopia. ${ }^{2}$ Department of Epidemiology and Biostatistics, Institute of Public Health, College of Medicine and Health Sciences, University of Gondar, Gondar, Ethiopia. ${ }^{3}$ Department of Health Promotion and Behavioral Sciences, Institute of Public Health, College of Medicine and Health Sciences, University of Gondar, Gondar, Ethiopia. ${ }^{4}$ Department of Health Systems and Policy, Institute of Public Health, College of medicine and health Sciences, University of Gondar, Gondar, Ethiopia. ${ }^{5}$ Department of Psychiatry, College of Medicine and Health sciences, Debre Tabor University, Debra Tabor, Ethiopia.
}

\footnotetext{
The original article can be found online at https://doi.org/10.1186/s13011020-00269-3.

* Correspondence: alexisersid@gmail.com

'Department of Public Health, College of Medicine and Health Sciences, Wachemo University, Hossana, Ethiopia

2Department of Epidemiology and Biostatistics, Institute of Public Health, College of Medicine and Health Sciences, University of Gondar, Gondar, Ethiopia

Full list of author information is available at the end of the article
}

Published online: 26 October 2020

\section{Reference}

1. Addila AE, et al. Alcohol consumption and its associated factors among pregnant women in Sub-Saharan Africa: a systematic review and metaanalysis' as given in the submission system. Subst Abuse Treat Prev Policy. 2020;15:29. https://doi.org/10.1186/s13011-020-00269-3.

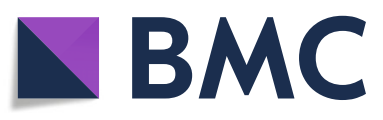

(0) The Author(s). 2020 Open Access This article is licensed under a Creative Commons Attribution 4.0 International License, which permits use, sharing, adaptation, distribution and reproduction in any medium or format, as long as you give appropriate credit to the original author(s) and the source, provide a link to the Creative Commons licence, and indicate if changes were made. The images or other third party material in this article are included in the article's Creative Commons licence, unless indicated otherwise in a credit line to the material. If material is not included in the article's Creative Commons licence and your intended use is not permitted by statutory regulation or exceeds the permitted use, you will need to obtain permission directly from the copyright holder. To view a copy of this licence, visit http://creativecommons.org/licenses/by/4.0/ The Creative Commons Public Domain Dedication waiver (http://creativecommons.org/publicdomain/zero/1.0/) applies to the data made available in this article, unless otherwise stated in a credit line to the data. 